\title{
Result-effects of the implementation of foresight technologies in the training of the future pharmacist
}

\author{
Viktoriia Nevolina*, Irina Mikhailova, Yuliia Moskaleva, Yuliia Yudaeva, and Kirill \\ Prokhodtsev
}

Orenburg State Medical University, Sovetskaya str., 6, 460000 Orenburg, Russia

\begin{abstract}
The professional training of a medical student is determined and predicted by the challenges of modern society. The active professional self-development of a pharmacist is aimed at the continuous development of new competencies in the field of scientific, practical and preventive medicine and pharmacy. Social priorities determine the student's professional self-development in modern pharmaceutical education, focused on the future needs of health care, presented in the predictive models of the future pharmacist. The concept of professional selfdevelopment of a future pharmacist has been developed and introduced into practice, which characterizes the goals, benchmarks, structural content, patterns, professional regulations, dynamics, result-effects. The pedagogical potential of a medical university in the professional training of a future pharmacist as an integrator of traditions and modern trends in the development of pharmacy has been determined; opportunities for the professional and personal growth of educational subjects; personification of scientific and pedagogical resources of teachers; an innovatively rich environment; modern network information and educational technologies. In the process of experimental work, we note the following result-effects: axiological dominants in the professional worldview of the future pharmacist on health management; interiorization of knowledge in the process of pharmaceutical practices; modeling the ethical and deontological foundations of the pharmacist's behavior; forecasting the professional future in the process of project implementation.
\end{abstract}

\section{Introduction}

The challenges of modern society pose serious demands for the development and integration of science and education. The achievements of modern science are ultimately realized in the concepts of education. The rapid development of biomedical science actively affects the modern sociocultural context and requires new approaches and technologies in pharmaceutical education. The educational basis and skills gained in the process of pharmaceutical education become a solid foundation for a competent and competitive future pharmacist, oriented towards social and professional responsibility, capable of

\footnotetext{
${ }^{*}$ Corresponding author: nevolina-v@yandex.ru
} 
introducing innovations and scientific achievements, and their further application in pharmaceutical practice. The deep interconnection and interaction of scientific research and educational process in the field of biomedicine and pharmacy requires the development and introduction of new promising concepts of professional self-development of the future pharmacist in medical educational institutions based on the integrative nature of biomedical knowledge and the achievement of modern pedagogical technologies.

A transdisciplinary analysis of the psychological and pedagogical support of the professional self-development of the future specialist revealed the prerequisites for solving the studied problem in science and practice. In pedagogical science, research is devoted to the study of the process of creative self-development of the personality (V.I. Andreev), the significance of professional contexts in the content of education (A.A. Verbitskii), the mechanism of value orientations and innovative challenges of the modern world in the processes of self-development of students (A.V. Kiriakova). The natural reflexive technology of self-development determines the personal mechanisms of this process (K.Ya. Vazina). The effects are justified: personal-professional self-development (L.N. Kulikova), the influence of the educational environment on personal self-realization (V.G. Maralov). The mutual influence of personal self-development and professional formation of a specialist (E.F. Zeer, E.A. Klimov), active moral position and professional success (I.A. Zimniaia) has been analyzed. Professional self-development is characterized as a process of self-improvement of the subject in the conditions of educational innovations and constructive professional interaction (I.D. Belonovskaia) [1-6]. The specifics and requirements of vocational training determine the personal, professional and social success of the self-development of the future pharmacist [7-10]. Trends in the professional ethos of the pharmacist, based on the traditions of pharmacy [11], influenced the implementation of foresight projects and the development of organizational and pedagogical conditions for the professional self-development of the future pharmacist. The expansion of the horizons of the pharmacist profession and the routing of the professional future are influenced by the innovations of pharmacy and "Medicine - 4P" (personalization, prediction, prevention and participation). The preparation of the future pharmacist is substantively updated by the contexts of modern medical pedagogy (A.I. Artiukhina); axiological priorities of the professional ethics of the pharmacist and medical deontology (N.V. Kudriavaia, I.V. Siluianova).

\section{Materials and Methods}

The analysis of the regional, Russian and international experience of biomedical and pharmaceutical education, professional training of future pharmacists made it possible to develop a conceptual study and implement research and experimental work in which students of the Faculty of Pharmacy and teachers of the Orenburg State Medical University (OrSMU) took part. The methodological foundations of the study were a set of mutually agreed approaches: integrative (allowed to consider integrative levels - interpersonal, interdisciplinary, interdepartmental, etc.); contextual (the study focuses on the meaningful context of pharmaceutical education, which is implemented in the means and technologies of professional training of students of the Faculty of Pharmacy); project (implementation of projects and design of strategies and tactics of professional self-development of future pharmacists) [12-13].

Based on these approaches, the psychological and pedagogical concept of professional self-development of the future pharmacist has been developed and implemented:

- benchmark (sustainable motivation of the future pharmacist to provide high-quality pharmaceutical assistance to the population);

- content (integration and improvement of personality potentials of a student of the 
Faculty of Pharmacy, interaction of subjects of biomedical education and the environment of a medical university);

- dynamics of achieving professional success of the future pharmacist (preliminary, orientation, setting, formative, adaptive, promising stage);

- means of pedagogical support (foresight projects, self-development technologies, pharmaceutical and simulation practices, the activities of a network experimental Foresight platform),

- result-effects (prospects for the development of professional and personal competencies of the future pharmacist).

Experimental testing of this author's concept has been carried out on the basis of real and virtual environments (OrSMU and network experimental Foresight platform). In the process of experimental work in order to form professional and personal goals and priorities of self-development, modern foresight technologies have been implemented with students of the Faculty of Pharmacy (scenario seminars, polls, foresight projects, scenarios, goal trees, analysis of social networks), modeling professional roles and activities of a pharmacist, designing strategies and tactics for professional self-development. The network experimental Foresight platform has been used as a virtual organizational support for organizing the interaction of network participants, questioning and testing modern pedagogical technologies and foresight projects.

State support, the development of social development programs, such as the "Comprehensive program for the development of biotechnologies in the Russian Federation and the implementation of "Medicine - 4P" also opens up new opportunities for biomedical and pharmaceutical training. The innovation of modern pharmacy leads to a rapid improvement in the potential of a medical university, which, in turn, contributes to increasing the educational and professional motivation of future pharmacists, interest in the profession, activating the independent work of students in the framework of research work, at clinical bases and on simulation practices.

The implementation of the synthesis of mutually agreed methodological approaches made it possible to identify the possibilities of a medical university for the professional and personal growth of the future pharmacist:

- integration of theory and practice, personalized in the scientific and pedagogical resources of teachers; application of remote educational technologies and e-learning in the implementation of the main professional educational programs of the specialty 33.05.01 Pharmacy (On-line interaction (training in real time) and Off-line interaction (work of subjects of the educational process at certain time intervals) (integrative approach);

- innovative and technologically rich environment of research laboratories, simulation center and tools (contextual approach);

- designing strategies and tactics for the professional self-development of the future pharmacist, modeling professional behavior in the simulation center (design approach).

The personality potential of the future pharmacist is expressed in the competence of pharmaceutical activities; axiological dominants on health management both personally and in relation to the population; humanistic guidelines of the professional worldview; professional responsibility; self-improvement projects in the field of pharmacy at the regional, federal and global levels. The integration of the potentials of subjects of medical and pharmaceutical education is implemented in the joint educational and professional activities of teachers and students: the study of the traditions of pharmaceutical activities on the basis of professional ethos and medical deontology; mastering the traditions and innovations of biomedical and pharmaceutical education; updating of interaction with practicing teachers at clinical bases and simulation centers; designing strategies and tactics for professional self-development of a future pharmacist; focus on foresight in the field of pharmacy. 


\section{Results and Discussion}

As a result of research and experimental work on the basis of a medical university and a network experimental Foresight platform using various methods (questionnaires, testing, polls) and technologies (gamification, quests, foresight technologies (foresight projects, expert polls, open discussions) at the ascertaining stage of the experiment, the specificity of the factors of professional self-development of students has been revealed on the basis of factor analysis. Among students-pharmacists, such basic factors of professional selfdevelopment as communication skills (0.76), experience of independent study work (0.74), experience in implementing plans (0.71), training program (0.69), professional competence $(0.62)$. The results obtained indicate that future pharmacists in the control and experimental groups have educational and cognitive motivation and a priority attitude to professional self-development in the field of pharmacy. To a lesser extent, students are able to implement various methods of design and self-organization, therefore, purposeful psychological and pedagogical support of the professional training of the future pharmacist is necessary.

Research work on the implementation of foresight technologies has been carried out within the framework of classroom, extracurricular and independent activities in three areas: educational (assessment of the resources of the pharmaceutical education system at the regional, Russian and international levels), innovation and prognostic (review and analysis of pharmaceutical innovations in the modern world, development of "Pharmacy of the future - a projection into the region" presentation complex, prospects for the development of innovative pharmacy in Orenburg region), professional and personal (review of strategies and tactics of professional self-development of a pharmacist specialization, policy, science, management, teaching, etc.).

Modern foresight technologies are implemented on the basis of OeSMU and the network experimental Foresight platform in the following aspects: foresight of health preservation and pharmacy of the future (healthy lifestyle 2030, "Pharmacist of the future", "Pharmacy of the future", "Ethical problems of modern medicine"); research activities (scientific referencing "The history of the formation of pharmacy", digest of pharmaceutical journals, scientific fund of pharmaceutical ideas); virtual interactions in the pharmaceutical community (virtual exhibitions "The Image of a Modern Pharmacist", "The History of Pharmacy in Persons", "Loyalty to the Profession of a Pharmacist").

The axiological vector of the implementation of the experimental research is aimed at: priorities of health and a healthy life, value orientations towards obtaining a pharmaceutical education and increasing the level of one's education, the value of developing oneself and one's professional abilities in the field of pharmacy. The effectiveness of the implementation of this direction is evidenced by the prevalence of such parameters of factor analysis as "health of mind and body", "predisposition to pharmaceutical activities", "research abilities" among students.

The gnoseological vector of the research is focused on students' comprehension of the determinants of professional self-development: external (image, standards of pharmacist labor, traditions) and internal (motives of educational and professional activities); awareness of resources and deficiencies of professional self-development; forecasting short-term and long-term prospects for self-development in the field of pharmacy; knowledge about the specifics of the professional ethos of the pharmacist. The priority parameters of the factor analysis among students have been: "research work", "disciplines of the social and humanitarian cycle", "deep modern biomedical education".

The praxeological vector of the research is aimed at the formation of the arbitrariness of professional self-development, the independence of goal-setting and planning, cognitive activity, and an adequate professional position. In the students' answers, the parameters "to 
act competently", "responsibility", “experience of self-education", "experience of independent work" began to prevail.

During the implementation of experimental work, we note the following results-effects: the prevalence of axiological dominants of health and a healthy lifestyle in the professional worldview of the future pharmacist; interiorization of knowledge in the process of pharmaceutical and simulation practices; synthesis of ethical and deontological foundations of educational and professional activities; designing a professional future in the process of implementing foresight projects "Strategy and tactics of professional self-development of a pharmacist".

The results of factor analysis showed that the students of the experimental group choose the parameters "professional competence" $(0.79)$, "purposefulness" $(0.75)$ and "research abilities" (0.71). Based on the results of factor analysis, we can state the positive dynamics of indicators of the structural components of the professional self-development of future pharmacists. In the control groups, the indicators of information and gnostic, activity and reflexive and regulatory components increased. In the experimental groups, the indicators of the motivational and value component also increased. The indicators of information and gnostic (from $23.78 \%$ to $41.15 \%$ ) and activity (from $25.59 \%$ to $43.19 \%$ ) components increased. There has been a jump in the indicators of the reflexive and regulatory component (the high level increased from $22.51 \%$ to $40.58 \%$ ). The dynamics of results is constructive and practice-oriented; it has proven the effectiveness of the implementation of pedagogical support in a network Foresight platform.

\section{Conclusion}

The specificity of the professional worldview of the student-pharmacist (axiological guidelines for personal self-development, professional ethos of the pharmacist, moral and ethical standards of pharmacy, the image of a modern specialist-pharmacist, personal resources in mastering the profession, awareness of professional risks) has been revealed. The use of the synthesis of integrative, contextual and design approaches in the course of experimental work made it possible to identify the result-effects of the implementation of foresight technologies in the preparation of a future pharmacist, which manifested themselves in the improvement of:

- the potential of the personality of the future pharmacist (motivation to provide highquality pharmaceutical care; competence of the professional activity of the pharmacist; moral guidelines of professional responsibility; projects of professional and personal selfdevelopment);

- the psychological and pedagogical potential of interaction between the subjects of the educational process (integration of traditions and innovations of pharmaceutical activity based on the professional ethos of a pharmacist and medical deontology; educational and professional activities updated by the contexts of pharmacy; interaction with practicing teachers; implementation of strategies and tactics of professional self-development focused on foresight pharmacy);

- the pedagogical potential of a medical university (knowledge-intensive environment of modern pharmaceutical education; synthesis of traditions and modern trends in the development of pharmacy; the possibility of professional and personal growth of the future pharmacist; personification of scientific and pedagogical resources of teachers; introduction of information educational technologies).

Informational, methodological and organizational support implemented on the basis of real environments (medical university) and virtual environments (network experimental Foresight platform) with the help of foresight technologies determines the network resulteffect - the formation of new relationships (students, teachers, practitioners, scientists, 
employers and other subjects with resources), accelerated network exchange of information, the creation of a technologically rich environment for interaction within scientific and educational medical clusters.

\section{References}

1. A.A. Verbitskii, Theory and Technologies of Contextual Education: A Study Guide (2017)

2. S.A. Miniurova, Psychology of Self-knowledge and Self-development: A Study Guide (2013)

3. V.V. Serikov, Personal Development in the Educational Process (2012)

4. E.F. Zeer, Education and Science, 5, 79 (2003)

5. E.A. Klimov, Psychology of professional self-determination (2005)

6. T.A. Olkhovaya, V.V. Nevolina, A.E. Shukhman, L.A. Amirovaand, N.A. Zaitseva, Iejme - Mathematics Education, 11, 467 (2016)

7. Order of the Ministry of Education and Science of the Russian Federation, 219 https://cdnimg.rg.ru/

8. Order of the Ministry of Labor and Social Protection of the Russian Federation, 91n https://profstandart.rosmintrud.ru/

9. Good Pharmacy Practice in the Newly Independent States, http://www.provisor.com.ua/

10. Order of the Ministry of Health of the Russian Federation, 647n https://www.garant.ru/

11. I.P. Voronkova, I.V. Mikhailova, N.A. Kuzmicheva, Orenburg Medical Guide, S4(24), 14 (2018)

12. V.V. Nevolina, E.B. Adigamova, A.V. Kostryukov, V.K. Vorobyev, V.N. Mikhelkevich, V.P. Akimova, Man in India, 97, 35 (2017)

13. V.V. Nevolina, R.K. Gilmeeva, V.A. Ignatova, M.Y. Fadeyeva, V.V. Kurushin, N.V. Kosolapova, V.A. Mishchenko, Eurasian Journal of Analytical Chemistry, 12(7b), 1117 (2017) 